\title{
TOMÁS NAVARRO TOMÁS: FONÉTICA, GEOGRAFÍA LINGÜÍSTICA, Y COMPROMISO POLÍTICO
}

\author{
STEVen Hess \\ Long Island University
}

\section{RESUMEN ESPAÑOL:}

Tomás Navarro Tomás, discípulo de Menéndez Pidal, se formó en Fonética y Dialectología en universidades francesa y alemanas. En Madrid, estableció el primer laboratorio fonético de España, y su «Manual de pronunciación» llegó a ser el clásico de la materia. Inició trabajos para un Atlas Lingüístico, frustrado por la Guerra Civil. Firme en su lealtad a la causa republicana, tuvo que exiliarse a Nueva York, donde prosiguió su carrera con estudios de dialectología (Puerto Rico), fonología, y métrica. Rotos sus lazos con España, su clásico manual quedó congelado en su última revisión (1932), a pesar de los avances hechos en la materia.

Palabras clave: Atlas Lingüístico, Américo Castro, Centro de Estudios Históricos, dialectología, dialecto puertorriqueño. fonética, fonología, Guerra Civil, lingüística española, Ramon Menéndez Pidal, métrica, Tomás Navarro Tomás, Federico de Onís.

\section{ABSTRACT:}

Navarro Tomás, a student of Menéndez Pidal, received training in phonetics and dialectology in French and German universities. In Madrid, he founded the first phonetic laboratory in Spain, and his handbook of pronunciation became the classic in the field. He began work on a Linguistic Atlas but was interrupted by the Civil War. His steadfast loyalty to the Spanish Republic caused his exile to New York at the end of the War. There, he published his research on Puerto Rican dialectology and did studies on phonology 
and metrics. He having broken all contact with Spain, his classic manual became frozen in its last revision (1932) despite subsequent advances in the field.

Key Words: Américo Castro, Center for Historical Studies, dialectology, Linguistic Atlas, Ramon Menéndez Pidal, metrics, Tomás Navarro Tomás, phonetics, phonology, Spanish Civil War, Spanish linguistics, Federico de Onís, Puerto Rican Spanish.

Cuando murió Tomás Navarro Tomás en 1979, había cumplido los noventa y cinco años y llevaba cuarenta exiliado en los Estados Unidos. Para esa fechas, el fundador de los estudios modernos de fonética, dialectología, y métrica españolas era una figura olvidada en su patria. Su larga ausencia se debió a una implacable oposición al régimen de Franco, que había borrado de la historia cultural el nombre del reconocido lingüista. Sin embargo, en Madrid un órgano del Estado, el Consejo Superior de Investigaciones Científicas (CSIC) seguía editando su Manual de pronunciación española, universalmente aceptada como la introducción imprescindible a la Fonética española, en reimpresiones inalteradas de la cuarta edición, de 1932, la última que revisó el autor antes de abandonar el país. Pero dichas ediciones «piratas» en el sentido que no le pasaron nunca a Navarro sus debidos derechos de autor (Carrasco), dejaban de identificar en las páginas del libro el nombre «T. Navarro Tomás» que llevaba la portada. La obra de Navarro, partiendo de una severa disciplina filológica, se veía interrumpida y alterada por el compromiso político en que se había metido el lingüista al estallar la Guerra Civil. Su lealtad a la causa republicana no sólo le acarreó a Navarro un destierro vitalicio, sino un olvido oficial y deliberado que duró hasta el final de la dictadura.

\section{Desde La Mancha a Alemania: la formación de Un lingüista}

Navarro Tomás nació en La Roda, pueblo de la provincia de Albacete (hoy integrada en Castilla-La Mancha) el 12 de abril de 1884, y allí estudió la primaria y dos cursos del Instituto, antes de terminar el bachillerato en Alicante. Luego pasó a la Universidad de Valencia para cursar la licenciatura, grado que terminó en Madrid, donde llegó a doctorarse bajo el magisterio de Ramón Menéndez Pidal (Fuster Ruiz 6)

A pesar de trasladarse muy joven a la capital, Navarro fue esencialmente un hombre del campo. Nunca perdería cierto aspecto rústico, según los recuerdos de una alumna suya, Carmen de Zulueta:»Tanto él [Navarro] como su mujer Dolores eran de la costa de Levante, de un pueblo de Albacete, y eran verdaderas gentes de pueblo... Yo no podía comprender cómo don Tomás se había hecho profesor de Fonética». (31)

Esta llaneza, que sorprendía a la hija de Luis de Zulueta (presidente de las Cortes durante la República), no le suponía obstáculo ninguno a la carrera de Navarro como lingüista. Todo lo contrario; su conocimiento íntimo de la vida rural y su trato juvenil con campesinos analfabetos le encaminaron a interesarse por descubrir los restos de dialectos arcaicos en pueblos remotos de la España de principios del siglo veinte. 
Una pensión de la naciente Junta para la Ampliación de Estudios le permitió a Navarro llevar a cabo encuestas dialectales y consultar archivos en el Alto Aragón. El 1 de noviembre de 1907 Navarro escribía a su maestro don Ramón:

Pude aprovechar el tiempo entre el lenguaje vulgar y los romances, aparte de los pergaminos. Caminando hacia Boltaña, recorrí varios lugarejos. No creeía encontrar tanto lenguaje aragonés como aún se conserva en esta parte de la montaña. (FRMP) ${ }^{1}$

Un artículo sobre el dialecto aragonés que salió en 1909 fue su primera publicación; compara el aragonés medieval de los documentos con el habla viva de principios del siglo. Su valiosa colección de textos medievales aragoneses casi se perdería durante la Guerra Civil y no se publicó hasta medio siglo después (1957).

Por entonces Navarro ingresó en el Cuerpo de Archiveros y Bibliotecarios, primero en Avila, y pronto trasladado a Madrid para poder trabajar por las tardes en el Centro de Estudios Históricos con Menéndez Pidal. Junto con otros dos discípulos de don Ramón, Américo Castro y Federico de Onís, emprendió en el verano de 1911 una encuesta dialectal en tierras leonesas. Don Ramón y sus aprendices terminaron por darse cuenta de que necesitaban ahondar más en los métodos de análisis fonético empleados en otros países. La solución convenida: Navarro Tomás fue mandado a ponerse al día en materia lingüística y pasaría casi dos años en universidades de Francia, Suiza, y Alemania.

Aprende a manejar los aparatos más puestos al día del laboratorio fonético de la Universidad de Hamburgo. Enterándole a don Ramón sobre los recursos y métodos de investigación que va conociendo a fondo, Navarro abriga la esperanza de que pronto lingüistas españoles, formados bajo su dirección, podrán superar a los extranjeros:

...Es verdad que hasta hoy la fonética tiene pocos aparatos propios. Fuera del cilindro registrador, de formas más o menos diferentes, casi todo lo que hay en estos grandes laboratorios son aparatos tomados a la física, todo grande, pesado, intransportable... Lo único practico es el paladar artificial. No hay nadie que haya salido con los aparatos al pueblo. Nosotros saldremos! (17 noviembre, 1913) ${ }^{1}$.

Sus estudios en Alemania han puesto a Navarro en contacto con la física, en su relación con las ciencias del lenguaje. Así la ciencia de laboratorio ha entrado por primera vez en el campo de la filología española, antes terreno casi exclusivo de humanistas, como precisa el historiador de la ciencia Sánchez Ron (2002). En otra carta, Navarro indica que ha pedido que le manden a Madrid aparatos suficientes para estrenar su propio laboratorio fonético en el Centro. Además, trayendo ejemplares de los mejores revistas en lenguas alemana y francesa, al volver a Madrid, Navarro ayudará a Menéndez Pidal a lanzar la Revista de Filología Española, que pronto seria el organismo más prestigioso del hispanismo.

\footnotetext{
${ }^{1}$ Las cartas de Navarro Tomás y de Américo Castro que se citan aquí se encuentran en el Archivo de la Fundación Ramón Menéndez Pidal (FRMP), Madrid, sección AEpistolario@ Le agradecemos a su Secretario, D. José Jesús Bustos Tovar, la autorización para utilizarlas.
} 


\section{El MANUAL CLÁSICO DE FONÉTICA}

A principios de 1913 Navarro está trabajando en el laboratorio fonético de la Universidad de Montpellier, bajo la dirección de Maurice Grammont. En carta de 12 de enero le comenta a Menéndez Pidal:

Le he dicho [a Grammont] que quiero hacer algo, un artículo corto, sobre fonética española, como recuerdo de su enseñanza... y hemos convenido que esto sea un ensayo sobre las vocales españolas, según mi propia pronunciación, sobre todo el timbre y la cantidad.

Navarro publicó los resultados de aquella experiencia de laboratorio en forma de una serie de artículos. El primero, «Siete vocales españolas,» lleva una curiosísima nota al pie de la página:

Mi pronunciación se ha formado en La Roda de la Mancha y en Madrid, en el ambiente universitario madrileño, pasa por pronunciación española correcta, sin influencia alguna regional (1916a:81).

Desde nuestro punto de vista, ésta es una afirmación audaz y poco científica. ¿Quién habría dicho que la pronunciación de Navarro era la «correcta»? ¿Siendo manchego, no tendría ningún rasgo regional cuando hablaba? Por cierto, aquella dicción manchegamadrileña no reflejaba el clásico castellano norteño de Burgos y Valladolid. Hoy día, la sociolingüística nos enseña que toda norma parte de alguna base geográfica, por modificada que sea en el curso de su evolución. Pero nuestros enfoques sociolingüísticos son muy posteriores a la época en que se formó Navarro. Su concepto de «norma sin rasgo dialectal» refleja preceptos lingüísticos de principios del siglo veinte.

En la misma $R F E$ en 1915 aparece como anónimo un alfabeto fonético para la transcripción del español, adaptación del sistema usado en Francia e Inglaterra. Aunque no se identifica Navarro como su autor, no cabe duda que fue invención suya. Considerando lo breve que fue el intervalo entre la estancia de Navarro en el extranjero y las publicación de Pronunciación en 1918, podemos afirmar que la primera edición también está basada, en mayor grado, en la pronunciación de su autor. En las primeras páginas del libro, Navarro formula su programa de «pronunciación correcta»:

Señálase como norma de pronunciación la que se usa corrientemente en la conversación de las personas ilustradas... Siendo fundamentalmente castellana, la pronunciación correcta rechaza toda forma local madrileña, burgalesa, toledana, etc.. Esta pronunciación, pues, castellano sin vulgarismo y culta sin afectación, estudiada especialmente en el ambiente universitario madrileño (1918: 6-7).

Con esta doctrina, Navarro parece abogar por una pronunciación culta sin base geográfica, idealizada, pero al mismo tiempo corrientemente oída en la Universidad de Madrid. Aquella primera edición subraya sólo lo castellano, pero en la cuarta de 1932, vemos que Navarro recoge favorablemente el seseo americano al mismo tiempo que rechaza el yeísmo: 
La opinión general en Castilla acepta el seseo andaluz e hispanoamericano... La lengua literaria, manteniendo la tradición histórica del idioma, distingue.. la ll y y $(1932: 94,135)$

Navarro reafirma esta doctrina castellanista en el folleto El español en el cine parlante (1930) donde insiste en que el cine sonoro, nuevo entonces, siga la pronunciación castellana tal como expuesta en su Manual, donde se describe la articulación de vocales y consonantes con un extremo rigor técnico. El mayor error doctrinal, sin embargo, estriba en la distinción que hace entre vocales abiertas y cerradas. A través de cuatro ediciones Navarro iba modificando ligeramente la regla de distribución de esas variantes, pero en realidad hay sólo cinco fonemas vocálicos, con un número variable de alófonos. El autor llegó a conocer la lingüística de la Escuela de Praga y colaboró en su publicación con un artículo sobre la distinción entre $\underline{o}$ abierta y $Q$ cerrada, en posición final de palaba en el dialecto andaluz, donde la variante abierta marca el plural; es decir muchacho es singular y muchacho = muchachos. Se valdría del término fonema muchos años después en su Fonología (1946) pero nunca empleó el término alófono.

El estructuralismo praguense se aplicará a la fonología del español con la obra de Alarcos Llorach (1950). En ésta, las observaciones fonéticas repiten, sin alteración alguna, la noción de distribución complementaria de alófonos vocálicos, remitiéndose a la Pronunciación de Navarro. Dicha idea se recoge todavía en en el curso de fonética para extranjeros elaborado por Quilis- Fernández y se repite en 1973 en el Esbozo de la Academia, cuya doctrina fonológica fue redactada por un lingüista tan cuidadoso como lo era Salvador Fernández Ramírez. Cabe observar que por muchos años ningún lingüista español se empeñó en volver al laboratorio, ni a las encuestas orales, para comprobar la validez de lo que había descrito Navarro. A pesar de ser oficialmente puesto en el olvido en España, por su condición de exiliado republicano, la generación de lingüistas formados en la postguerra seguían guardando una fe inquebrantable en la Fonética de Navarro Tomás.

El primer giro doctrinal respecto de los fonemas vocálicos no se produjo en España, sino en los Estados Unidos, más notablemente a través de sucesivas ediciones del texto escolar de Dalbor, quien iba reconsiderando las principales cuestiones de fonética y fonología españolas. ${ }^{2}$

La existencia de una distribución complementaria de vocales abiertas y cerradas no fue rechazada a base de pruebas extensivas de laboratorio hasta 1993 cuando Antonio Quilis publicó su Tratado. Director del Laboratorio Fonético que había fundado Navarro en Madrid, Quilis apunta una situación de variación libre «dada la imposibilidad de sacar ninguna repetición constante entre los informantes encuestados» $(143)^{3}$.

Hay otros errores, debidos a observaciones mal interpretadas, o al habla exclusivamente madrileña de los sujetos que Navarro llegó a examinar. Analizando la

\footnotetext{
${ }^{2}$ Dalbor, en su primera y segunda ediciones $(1969,1980)$ da dos alófonos, abierto y cerrado, para el fonema /e/ y solo uno para el /o/. En la tercera (1997), Dalbor ha suprimido la [ę] abierta, explicando, "Our experience has subsequently shown that this allophone is virtually redundant in Spanish..." (142n1).

${ }^{3}$ La diferencia entre la doctrina de Navarro y la realidad de la pronunciación madrileña fue notada por Rice, a base de su experiencia como alumno del Curso para Extranjeros en 1928. Rice apunta que otros profesores del Centro tendían siempre a preferir las variantes abiertas sobre las cerradas, contrariando así las indicaciones del Manual.
} 
pronunciación de la conjunción $y$, Navarro distingue cuatro realizaciones a) entre dos consonantes, se pronuncia con [i] plenamente vocal, eg. «pan y vino»; b) entre consonante y vocal, se convierte en la semiconsonante [j]: c) «hablan y escriben» entre vocal y consonante, aparece la semivocal [i]: «blanco y negro». Lo que sí sorprende es la cuarta variante: d) «entre vocales toma aproximadamente el sonido de la palatal fricativa [y]: [«este y aquel] [este yakél]» (Pronunciación 50). Navarro no da lugar a una pausa, la que suprimiría semivocal o semiconsonante, o sean, alófonos «deslizados». Aquí ocurre más bien una vocal deslizada que no una consonante fricativa /y/. El estudio de las consonantes, en cambio, ha conservado plena validez, aunque también refleja conceptos pre-fonológicos. Por ejemplo, Navarro describe minuciosamente siete consonantes nasales: bilabial, labiodental, alveolar, interdental, dental, palatal, velar. Ahora diremos que sólo hay tres fonemas nasales $\operatorname{lnl}|\mathrm{m}| \mathrm{Iñ} \mid$, con varios alófonos que se producen según el contorno fonético y el dialecto del hablante.

La llegada definitiva de Navarro Tomás a los Estados Unidos en 1939 amplió considerablemente el prestigio del Pronunciación. en reimpresiones llegadas desde Madrid, o hechas en Nueva York. En esta ciudad apareció en 1957 una quinta edición, inalterada salvo un corto capítulo sobre dialectología hispanoamericana. Quizás el dolor del exilio le haya impedido a Navarro volver a un tema tan íntimamente ligado a su vida y labor en España. Sobre la congelación del Manual en su versión de 1932 escribe el lingüista Pedro Álvarez de Miranda:

¿Qué hubiera pasado si Tomás Navarro Tomás hubiera seguido de verdad renovando y revisando su «Manual», cosa que no hizo? Pues -creo yo- que esa descripción oficial de la fonética española hubiera seguido evolucionando y cambiando, en vez de quedar como paralizada, repetida hasta la saciedad en la innumerables reimpresiones del libro... y merced a su adopción por otros: Quilis, Alarcos.... ¿Quién podía pensar que la guerra civil afectase a algo tan alejado de ella como la fonética? Sin embargo, así fue (1999).

A pesar de sus defectos teóricos o pedagógicos, Pronunciación queda como la contribución más influyente en la historia moderna de la fonética española. Al igualar el concepto de pronunciación correcta con la castellana- y ésta supuestamente desprovista de rasgos dialectales- Navarro hacía una labor de propaganda cultural a favor de España. Se impartió la doctrina castellanista de don Tomás por mucho tiempo, hasta en Estados Unidos, a pesar de la nutrida presencia de hispanoamericanos.

El rigor de la investigación empírica que exigen los estudios de Fonética no impidió que Navarro formara discípulos. Samuel Gili Gaya inició sus aportaciones con «Algunas observaciones» (1922) y acabaría por elaborar una introducción sucinta pero sustancial a la fonética general (1950). Amado Alonso, siguiendo el ejemplo de su maestro, pasó dos años estudiando Fonética en Hamburgo (1922-24). Aunque se le conoce más por sus estudios de estilística, en los últimos años de su vida preparó una magna obra de fonética histórica, De la pronunciación medieval a la moderna en español, que la muerte dejó inconclusa e inédita hasta que Rafael Lapesa la revisó y preparó para la publicación. Y como colofón, en los últimos tiempos de la República, Navarro formó a dos discípulos de una nueva generación, Alonso Zamora Vicente y Maria Josefa Canellada, luego unidos por el matrimonio, que harían sus carreras en la España de postguerra. (Zamora Vicente). 


\section{Puerto Rico: COMIENZOS DE LA GEOGRAFÍA LINGÜÍSTICA}

Habiendo dado un curso de verano en 1925 en San Juan, Puerto Rico, Navarro volvió a la isla en 1927 como profesor invitado por la recién fundada Universidad. Con coche y chófer oficiales, se lanzó a recorrer cuarenta y seis «municipios» para preparar un estudio exhaustivo del dialecto puertorriqueño. El cuestionario provisional que utilizó saldría como folleto unos quince años después (Navarro 1943) y serviría de guía para bastantes estudios dialectológicos. Las encuestas en Puerto Rico quedaron almacenadas durante veinte años, hasta que Navarro, establecido en Nueva York, las publicó, acompañadas de un pequeño atlas lingüístico (1948). Es el primer estudio, hecho con métodos científicos, sobre el español del Nuevo Mundo. ${ }^{4}$ Investigación minuciosa de la fonética del español borinqueño, el libro de Navarro presta relativamente poco atención a la morfología, sintaxis, o léxico, este último quizás, visto desde hoy, el aspecto más interesante del dialecto. En material de fonética Navarro deja de ofrecer una explicación plausible de la pronunciación velar de la /rr/, que remplaza la articulación alveolar en gran parte de la isla; alófono raro en el mundo hispanohablante, esa [R] se asocia típicamente con las clases rurales puertorriqueñas. Navarro no queda satisfecho con ninguna de las teorías ponderadas por otros estudiosos sobre posible sustrato indígena o adstrato africano para explicar la [R] velar puertorriqueña.

Las encuestas de Navarro en Puerto Rico se hicieron noticia de prensa cuando regresó a España. Entrevistado por el prestigioso quincenal La Gaceta Literaria, comentaba el dialectólogo:

Mi objeto ha sido estudiar el habla popular de los pueblos más apartados . . y entre los sujetos que por su aislamiento y falta de instrucción representaba más propiamente la tradición popular. (Gaceta 1928)

Esos preceptos -ambiente rural e informantes analfabetos- arrancan de la lingüística de raíces románticas fundada en Alemania a principios del siglo diecinueve, y todavía vigente en Hamburgo donde Navarro se había iniciado en geografía lingüística. Sus investigaciones puertorriqueñas eran un ensayo para un futuro atlas español. Pero había un fallo generacional; en los años 1920 ya no serían campesinos los únicos sujetos idóneos para la dialectología. El valor «tradicional» del ambiente rural había cedido ante el creciente peso cultural de los centros urbanos, deliberadamente pasados por alto en la obra de Navarro. Este enfoque metodológico, tenazmente seguido por Navarro y sus discípulos habría de ser parcialmente superado para la época del Atlas Lingüístico de la Península Ibérica (ALPI).

Como complemento de su estancia en Puerto Rico, Navarro pasó algún tiempo en la República Dominicana. Sus ficheros sobre el español dominicano también fueron archivados durante décadas, como un tesoro escondido que no se debiera desvelar demasiado pronto. En este caso la demora resultó improductiva; cuando salió su

${ }^{4}$ La influencia duradera de las estancias de Navarro (1925; 1927-28) en Puerto Rico es uno de los temas principales de Naranjo, et al., 2002. 
vistazo sobre el español dominicano (1956), la tardanza casi anuló la validez de aquella encuesta.

\section{GEOGRAFÍA LINGÜÍSTICA DE ESPAÑA: ALPI}

Al volver de Puerto Rico, Navarro se puso a planear un atlas lingüístico español. Menéndez Pidal ya lo había soñado desde joven, pero absorto en investigaciones sobre el Cid, el Romancero, historia de la lengua y Crónicas medievales, aceptó ser director, con tal de que Navarro fuera el coordinador efectivo (Pérez Pascual 2008). Falta de dinero, las encuestas no pudieron empezar hasta 1932, cuando se formaron tres grupos: Aurelio M. Espinosa, Jr., y Lorenzo Rodríguez Castellano, para el dominio castellano; Manuel Sanchis Guarner y F. Borja Moll, para el catalán; Aníbal Otero y F. Nobre Gusmão, para el gallego-portugués. De las encuestas acabadas antes de la guerra, salieron artículos de Navarro y sus discípulos sobre la frontera del andaluz, y el valenciano, además de la tesis doctoral de A.M. Espinosa, Jr.

Después de estallar la guerra, Navarro llevó las materias reunidas para el futuro Atlas a Valencia, luego a Barcelona, y finalmente a Nueva York, donde las depositó en Columbia University, maniobra no para hacerse con ellas, sino para salvarlas de la furibunda ola destructora de los fascistas. Cuando vino la guerra fría, y Estados Unidos firmó el acuerdo económico-militar con la España franquista, Navarro abandonó toda esperanza de volver a su patria. (Navarro 1975) A través de la mediación de Rafael Lapesa, Navarro recibió a Sanchis Guarner y Rodríguez Castellano en Nueva York para entregarles el incompleto atlas (Lapesa 1980), consintiendo en que se publicara por el CSIC, organismo que había remplazado a la fenecida Junta, borrada de la memoria «oficial» a causa de su liberalismo. Un primer tomo del ALPI, único jamás publicado, salió en 1962, señalando a Navarro y a Rafael de Balbín como codirectores. Luego sucedieron las fotos en la prensa, con Menéndez Pidal y los encuestadores (dos de ellos ex-presos políticos). Esa propaganda periodística no era más que «pastelería» porque tras aquel acto no se publicó nada más.

Si los materiales del ALPI se encontraran en la sede del CSIC en Madrid, ¿por qué no llegarían a publicarse más tomos del proyecto iniciado y acariciado por Navarro Tomás? Pérez Pascual, con extremo tacto, ha desvelado una explicación muy plausible: «Puede vincularse la interrupción del ALPI con la publicación meses antes del Atlas Lingüístico y Etnográfico de Andalucía, la que inauguraba toda una serie de atlas regionales dirigidos por Manuel Alvar» (2008: 424).

Un lingüista que hacía carrera a caballo entre Estados Unidos y España, Diego Catalán comentaba en 1974, «R. de Balbín, junto con M. Alvar, son sin duda las personalidades que han influido más en la investigación lingüística en plano nacional, oficial. En esta posición directiva, Balbín y Alvar vienen a ocupar, en la España de las

\footnotetext{
${ }^{5}$ Alvar 1969 reseña los atlas lingüísticos de la Romania, antes de exponer los nuevos métodos empleados en la series de atlas lingüísticos regionales que empezaba a dirigir en España. Intenta anular los métodos y el valor de los datos del único tomo del ALPI.
} 
últimas décadas, el papel que había tenido Menéndez Pidal en la Monarquía y la República» (124).

Y así en su exilio definitivo Navarro Tomás sufrió la hostilidad del CSIC franquista. Nada más sobre el frustrado ALPI apareció durante cuatro décadas, hasta que un romanista canadiense, David Heap, se puso a recoger los restos dispersos del Atlas, con el anunciado plan de publicarlos en Internet. (Heap).

\section{GUERRA CIVIL Y COMPROMISO POLÍTICO}

Al estallar la guerra en julio, 1936, el director de la Biblioteca Nacional, Miguel Artigas, se encontraba en la zona de los rebeldes, y el Gobierno de la República nombró a Navarro para sucederle. Al mismo tiempo don Tomás fue designado vice-presidente de la Junta de la Protección del Tesoro Artístico. Para contestar las acusaciones que hacía Artigas sobre los supuestos desmanes cometidos por los «rojos», Navarro escribió una carta abierta a los profesores de español estadounidenses (AATS) como réplica:

Nuestros amigos extranjeros pueden estar seguros que de parte del pueblo ningún peligro han corrido ni el Museo del Prado ... ni la Biblioteca Nacional, ni la del Palacio, ni la de Escorial, ni las Academias, ni en fin, la de ningún centro de carácter científico o literario. (1937b)

El Tesoro Artístico sería embalado y enviado, sucesivamente, a Valencia, Barcelona, y cuando terminaba la lucha, a Ginebra, Suiza, para ponerlo a salvo. Se consideraban parte de dicho tesoro los papeles de Menéndez Pidal, un archivo que incluía el patrimonio nacional que era el Romancero. Aquel acto de reconocimiento de parte de Navarro reflejaba una deuda duradera para con su maestro, a pesar de las relaciones oficiales cada vez más tirantes, entre don Ramón y la República (Catalán 2001. I: 217-38).

Mientras progresaba la guerra, Navarro se iba perfilando como el máximo propagandista de la España leal. Se hizo patente su entusiasmo por el comunismo cuando viajó a la Unión Soviética en noviembre de 1937, con motivo del vigésimo aniversario de la Revolución rusa. Vuelto a Valencia, Navarro publicó un folleto que incluye una crónica de ese viaje oficial, 1936-1938. Dos años de leal amistad. España en la Unión Soviética, de unas veintitrés paginas. Entre otros elogios del Estado comunista, don Tomás observa: «En la Unión Soviética se siente la causa del pueblo español con solidaridad verdaderamente fraternal. En España estos hechos no son bastante conocidos o a lo menos bastante divulgados.» (14)

Y luego, pasa a criticar el capitalismo reinante en España:

Las informaciones y comentarios [de los rusos] dedicados a España con motivo de la guerra han puesto de relieve el atraso cultural y económico de la mayor parte de nuestras provincias, la injusta y desigual distribución del trabajo, de la propiedad y de la riqueza, la tradicional y abusiva influencia de las clases privilegiadas del país. (18)

Hay que tener presente que en aquel entonces el Ministro de Instrucción Pública, organizador del viaje a Rusia, era el comunista Jesús Hernández. No podemos saber si las 
convicciones expuestas por Navarro venían de creencias arraigadas desde hacía mucho tiempo, o si eran producto circunstancial de la guerra. Lo que sí consta es el tono muy subido de ese folleto, ausente de muchas bibliografías de Navarro; sin embargo, figura en la más completa, la de Beardsley, bajo el título inocuo «Mi viaje a Rusia».

Para 1937, su amigo de treinta años, Américo Castro, se había negado a sumarse a la causa republicana y escogió el camino del exilio, aceptando una oferta del Instituto de Filología de Buenos Aires, dirigido por Amado Alonso. Al saber que Castro prefería quedarse alejado de la patria en llamas, Navarro cogió la pluma para mandar al periódico antifascista El Mono Azul una «Carta a un intelectual expatriado», en la que, sin llamar a don Américo por su nombre, pasaba a criticarle duramente:

... Conviene que sepas que se te censura es concretamente el que no estés aquí ocupando tu puesto y prestando la ayuda que de un hombre de tus condiciones y significación cabía, es peor. Las razones de carácter personal o familiar no significan nada ante el pleito como el que se está disputando. (1937a)

Castro se sintió profundamente herido y, desde la Universidad de Wisconsin el 11 de noviembre de 1937, le escribió a Menéndez Pidal, explicándole que su exilio se debía a razones de familia: «... Es increíble que Navarro se haya lanzado a adobar esa retórica carta, para dejarme en mala postura... Navarro tenía que pensar que mi ausencia obedecía no a miedo ni a egoísmos, sino a razones de mucho fondo... Nosotros podemos hacer lo que podemos, pero meter a los hijos en ese fregado, no es lícito».

Así se quebraba una amistad de tres décadas, nacida y acrecentada en labores comunes en el Centro. Irónicamente, los dos contrincantes acabarían por continuar su carrera docente casi como vecinos -Castro en Princeton, y Navarro en Columbiapero, a pesar de esa cercanía geográfica, la Guerra Civil había abierto una brecha insalvable.

Pero antes, Navarro había vivido las fortunas, cada vez más adversas, de la República hasta la última hora. Pudo salir de Barcelona pocas horas antes de la llegada de las tropas nacionales, y pasó la frontera en compañía de Antonio Machado, quien se pararía en el pueblecito de Colliure, donde moriría al mes siguiente. De su parte, Navarro intentó ayudarles al poeta y sus familiares: «Desde Perpignan, donde se había desplazado, Navarro Tomás le trajo a don Antonio una carta oficial del Ministerio del Estado de la República Española en la que decía que la Embajada republicana en Paris tomaba a cargo todos los gastos de él y de su familia» (Salberria 131).

Quebrantos y afianzamientos de viejas amistades: mientras Navarro se rompía con Castro, Federico de Onís, catedrático y jefe del Departamento de Español en Columbia University, les mandó a Navarro y Antonio Machado conjuntamente una carta de adhesión a la causa republicana:

....Nunca he hecho una declaración de adhesión a ningún régimen o partido político durante la Monarquía o la República; pero en el momento crítico actúal que se encuentra en peligro un Gobierno que, en circunstancias dificilísimas ha logrado organizar a un pueblo heroico que se está muriendo por las ideas en que yo creo, yo declaro mi solidaridad completa con ese pueblo y su Gobierno. (Salberria: 116-17) 
Aun más penosa que la ruptura con Castro habría sido para Navarro la destitución de Menéndez Pidal, exiliado en Nueva York, como Director del Centro que había fundado y dirigido desde 1910. No queriendo apoyar a la República desde el extranjero, y temiendo represalias contra su esposa, hija y otros familiares residentes en Segovia, zona nacional, Menéndez Pidal escribió al Embajador en Washington, Fernando de los Ríos, declarando que no podía volver a ocupar su puesto en España. Por eso, el Gobierno de la República se desentendería de Menéndez Pidal para el resto de la Guerra. (Catalán 2001, I:230-34) A partir de entonces (diciembre, 1937), Navarro dejaría de escribirle a Menéndez Pidal, empezando así un silencio permanente. Ni Navarro ni Menéndez Pidal nunca hicieron alusión pública a la ruptura que había impuesto la Guerra Civil. Sin embargo, a la muerte de don Ramón, Navarro mandó una carta (14 dic. 1968) a su antiguo discípulo y colabordor del ALPI. Lorenzo Rodríguez Castellano, en la que comenta:

... su larga vida, que ha sido, además, tan rica, brillante y lograda. Pocas se le pueden comparar. Será difícil que nadie pueda llenar el vacío que deja en el mundo de la cultura española ...

Es de lamentar que su actitud de su obra científica quedaría como incomparable modelo de inteligencia quedaría como superior y de integridad superior. (Santi Cortés, Historia externa del ALPI, pág. 40)

Vemos en esta carta que Navarro consideraba el compromiso político como cuestión de «integridad personal» sin entrar en detalles, podemos contestar que la avanzada edad de don Ramón, la presencia de su biblioteca y archivo en Madrid, sin olvidar a su esposa y otros familiares a quienes les negaron el pasaporte para emigrar, eran factores principales que le aconsejaban volver a España (v. Catalán, Vol. I; Pérez Pascual). Menéndez Pidal siempre evitó todo compromiso político; Navarro, en cambio, se comprometió de todo corazón con la causa republicana. Sin embargo, a la muerte de don Ramón, Tomás Navarro, entonces con ochenta y cinco años de edad, se sumó a un homenaje mexicano para recordarle a su maestro en términos que nos conmueven todavía:

Sería difícil señalar en la España contemporánea otro hombre de obra tan fecunda, ni de vida tan lograda, ni tampoco de mayor urbanidad y pulcritud en sus costumbres y maneras... Los que tuvimos el privilegio de recibir sus enseñanzas guardamos, además, en lo hondo de nuestro afecto, la entrañable memoria de su cordial imagen de maestro de maestro y amigo. (1968-69:24)

\section{NAVARro TOMÁs EXILIADO EN NUEVA YoRK}

En España, Navarro nunca había sido catedrático, sino oficialmente «bibliotecario/archivero». Cuando llegó la República, y las reformas iniciadas según el Plan Morente, Navarro fue llamado a dar cursos de Fonética en la Facultad de Filosofía y Letras como «profesor». Su trabajo principal, en el Centro, lo llevaba a cabo como «Bibliotecario» del mismo desde 1922. Hay que recordar que en esa época la Universidad de Madrid contaba con sólo dos catedraticos de Filología española: Menendez Pidal -«Filología románica»- y Américo Castro -«Historia de la lengua 
española»- (Bustos Tovar 2009). Tras una breve estancia en Francia, Navarro llegó a Nueva York. Se quedaría allí como Profesor de Filología Española en Columbia University hasta cumplir los 68 años, entonces edad de jubilación reglamentaria. Eran pocos los españoles que llegaron a Estados Unidos; ese privilegio les correspondió a un grupo muy selecto. «Estados Unidos adoptó una política migratoria muy restrictiva de cara a la acogida de exiliados españoles. Sólo fueron admitidos intelectuales que tenían un prestigio consolidado... Una parte importante de este profesorado procedía del Centro de Estudios Históricos de Madrid» (Alted 302).

El ambiente político de Estados Unidos durante la Segunda Guerra Mundial, liberal pero fuertemente anticomunista, habría hecho que se sepultara para siempre la anterior afiliación izquierdista de Navarro Tomás, quien se hizo ciudadano estadounidense en 1946. Recluido en un «castillo interior,» en palabras de Malkiel (181), el lingüista se ceñía a investigaciones filológicas, sin volver jamás a pisar terreno ideológico. Mientras tanto su colega de antaño, Américo Castro, reorientaba su papel de historiador cultural con una tesis atrevida («cristianos, moros, y judíos») que daría lugar a controversias y polémicas que han continuado hasta hoy día. Sobre la pervivencia de la antipatía hacia Navarro, Castro le escribió a Menéndez Pidal el 21 de junio, 1943: «No veo a N[avarro], que además de no entender nada más fuera de las vocales y las consonantes, es un caso límite de especialismo intelectual.»

En Columbia, Navarro tuvo menos éxito que antes en atraer discípulos. En aquella época- años cuarenta y cincuenta- la filología iba a la zaga de los estudiosos literarios en Norteamérica, como apunta Malkiel, valiéndose de recuerdos personales no exentos de cierta amargura. Sin embargo, Navarro, animado por un interés nuevo en la cultura sefardí, dirigió en 1944 la tesis de Maestría de Denah Levy [Lida], «La pronunciación del judeoespañol esmiriano en Nueva York» (BenUr 169-171). Otro discípulo, Daniel N. Cárdenas, se doctoró con «El español de Jalisco.» ${ }^{6}$ Por aquellas fechas, Navarro publicaba estudios sobre la versificación de poetas individuales, luego reunidos en Los poetas en sus versos. Lecturas sistemáticas eran complementadas por los trabajos que entregaban alumnos de Columbia, una de la pocas universidades que ofrecían un cursos posgraduado sobre «Métrica española» y bajo este título Navarro preparaba su gran obra de consulta sobre la materia. Navarro fue parte íntegra y muy activa de un profesorado que contaba con Onís, Ángel del Rio, Francisco García Lorca, Andrés Iduarte, Eugenio Florit. Con ese plantel, su Casa Hispánica, y la publicación de la Revista Hispánica Moderna, Columbia por mucho años fue un foco principal del hispanismo.(Carrasco Urgoiti). ${ }^{7}$

Yakov Malkiel, en una necrología incompleta y, en varios extremos, errónea- le culpa a Navarro el no haberse acogido suficientemente a los progresos hechos en el

${ }^{6}$ Cárdenas 1967 es una edición inalterada de la tesis doctoral que había entregado en 1953, a base de encuestas hechas en 1949. En este caso, el lapso de catorce-o dieciocho-años resultó desastroso para la recepción del estudio. Boyd Bowman 1969 lo acogió con bastante reserva, mientras que la reseña de Craddock 1970 fue francamente negativa. Los dos lingüistas norteamericanos hicieron hincapié en el error que había hecho Cárdeas al seguir servilmente el Cuestionario de Navarro, un método que ya consideraron inadecuado y superado.

${ }^{7}$ Maria Soledad Carrasco Urgoiti (1922-2007) fue alumna de Navarro en Columbia entre 1946 y 1954. Llegó a ser reconocida especialista en el Siglo de Oro y catedrática de la City University of New York. Siendo española (Licenciada, Madrid, 1944), pero no «exiliada» en el sentido político, ni lingüista, recordó con objetividad el impacto que hizo Navarro en Columbia University. 
campo de la Fonología durante sus años en Columbia. Creemos poder explicar por qué Navarro se hubiera resistido a entrar en temas de fonología estructuralista y hasta generativa. Nuestro lingüista nunca se dedicó a la elaboración de doctrinas teóricas o esquemas cuasi matemáticos; fue siempre un fonetista de laboratorio y encuestador de campo- labores sumamente arduas, pero positivistas. En su largo exilio norteamericano, pudo terminar varios proyectos de conjunto que había empezado en España: Entonación (1944); Puerto Rico (1948); Métrica (1956). Es evidente que esa obra linguiística refleja orientaciones metodológicas (y teóricas) típicas de los años 1920quizás aun antes. Pero este atraso en nada disminuye su valor como admirables obras de referencia. Comenta Diego Catalán, Navarro en América «no se desvió de la ruta iniciada» (1974:114). Aquella ruta inicial encaminó a un merecido reconocimiento en el mundo del hispanismo por un legado lingüístico de valor duradero.

\section{LA MEMORIA DE NAVARRO, RECUPERADA}

Tomás Navarro Tomás murió el 12 de septiembre, 1979 en Northhampton MA, donde su hija Joaquina era profesora de Smith College. España había entrado en la transición» entre la larga dictadura franquista y la nueva monarquía constitucional. Unos leales discípulos, Rafael Lapesa y Alonso Zamora Vicente, escribieron necrologías muy sentidas, elogiando la obra y la figura de su maestro. Dentro de pocos años, la descentralización de la cultura española, en el Estado de las Autonomías, resultó en el reconocimiento oficial de Navarro por su patria. El Colegio Público de La Roda lleva su nombre, y también, el Instituto de Enseñanza Superior de Albacete. En 2007, un homenaje oficial de su pueblo natal fue presidido por el Alcalde de La Roda (12 de abril, aniversario 123 de su nacimiento), seguido de otro en la Biblioteca Nacional (16 de abril) que Navarro había dirigido en aquellos sombríos días de 1936. Y como recompensa de una preterición demasiado larga e injusta, el Consejo Superior de Investigaciones Científicas, al inaugurar la sede de su nueva biblioteca de Humanidades ( descendiente directa de la misma que había cuidado don Tomás en el Centro) le puso el nombre «Biblioteca Tomás Navarro Tomás» (23 de febrero, 2009). Navarro Tomás ha terminado por ser honrado en España por su labor de profesor, lingüista, bibliotecario, y sin confesarlo en tantas palabras, de leal republicano. Con la actual «recuperación de la memoria histórica» se ha recuperado una de las glorias de la Edad de Plata de la cultura española.

\section{OBRAS CITADAS:}

ALPI, 1962. Atlas Lingüístico de la Península Ibérica. I. Fonética, 1. Madrid: CSIC.

Alarcos Llorach, Emilio, 1950. Fonología española. Madrid: Gredos. 4a ed. rev. 1965.

Alonso, Amado, 1955. De la pronunciación medieval a la moderna en español. I. Madrid: Gredos. II, 1969.

Alted, Alicia, 2005. La voz de los vencidos: El exilio republicano de 1939. Madrid: Aguilar.

AlVAR, Manuel, 1969. Estructuralismo, geografía lingüística y dialectología actual. Madrid: Gredos.

Álvarez de Miranda, Pedro, 1999. Carta personal al autor. Madrid: 12 Sept. 
BeARdSLey, Theodore S., Jr., 1971. Tomás Navarro Tomás: A Tentative Bibliography 1908-1970. Syracuse: Syracuse U Centro de Estudios Hispánicos.

Ben-Ur, Aviva, 2009.. Sephardic Jews in America. New York: NYU Press.

BoYd-Bowman, Peter, 1969. reseña, Cárdenas 1967. Hispania 52: 335-36.

Bustos Tovar, José Jesús, 2009. «Los estudios de lingua española y de filología románica,» La Facultad de Filosofia y Letras de Madrid en la Segunda República. Madrid: Sociedad Estatal de Conmenoraciones Culturales. 324-43.

Cárdenas, Daniel, 1967. El español en Jalisco. Madrid: CSIC.

CARrasco Urgorti, María Soledad, 1998. Entrevista con el autor. Madrid: 4 de julio.

CATALÁn, Diego, 1974. Lingüística íbero-románica: crítica retrospectiva. Madrid: Gredos.

- 2001.. El Archivo del Romancero: Patrimonio de la Humanidad. 2 tomos. Madrid: Fundación Ramón Menéndez Pidal.

CRADDOCK, Jerry R., 1970. reseña, Cárdenas 1967. Hispanic Review 38: 422-25.

Dalbor, John B., 1969. Spanish Pronunciation: Theory and Practice. New York: Holt. 2a ed. 1980; 3a ed. rev. 1997.

Espinosa, Aurelio M., Jr., 1935. Arcaísmos dialectales: La conservación de «s» $y$ «z» sonoras en Cáceres y Salamanca. RFE Anejo 19. Madrid: Junta para la Ampliación de Estudios.

Fuster Ruiz, Francisco, 1980. In Memoriam: Tomás Navarro Tomás». Al-Basit: Revista de Estudios Albacetenses 7: 5-36.

GiLi GaYA, Samuel, 1950. Elementos de fonética general. Madrid: Gredos. 4a ed. 1961.

La Gaceta Literaria, 1928. «Los raids lingüísticos: Navarro Tomás: Vuelto de América.» 1 diciembre: 3.

HeAP, David, 2002. Segunda noticia del ALPI (a los cuarenta años de la publicación del primer tomo).» RFE 82: 5-19.

LAPESA, Rafael, 1970. «Navarro Tomás: Vida y obra de un noble varón». Insula 395 (Oct.): 3.

LEVY, Denah, 1952. «La pronunciación del sefardí esmiriano de Nueva York». NRFH 6: 277-81. (Resumen de su tesis, M.A. Columbia, 1944.)

MALKIEL, Yakov, 1981. «A Hispanist Confined to His Inner Castle»: Tomás Navarro Tomás (18941979) [sic].R Ph 24 Special Issue (Feb): 98-115.

NARANJo, Carmen, et al., 2002. Los lazos de la cultura: El Centro de Estudios Históricos de Madrid y la Universidad de Puerto Rico, 1916-1939. Madrid: CSIC.

NAVARRo TOMÁs, Tomás, 1909. «El perfecto de los verbos en -ar en aragonés antiguo: Observaciones sobre el valor dialectal de los documentos notariales». Revue de Dialectologie Romane 1: 110-21.

— 1916a. «Siete vocales españolas.» RFE 3:51-62.

— 1916b. «Las vibraciones de las vocales acentuadas.» RFE 3: 166-68.

— 1916c. «La cantidad de las vocales acentuadas.» RFE 3: 387-408.

— 1917. «Cantidad de las vocales inacentuadas.» RFE 4: 371-88.

- 1918a. «Diferencias de duración entre las consonantes españolas.» RFE 5: 367-93.

- 1918b. Manual de pronunciación española. Madrid: Junta para la Ampliación de Estudios (Publicaciones de la Revista de Filología Española. III). 2a ed., 1921. 3a ed. 1926. 4a ed., 1932. $5 a$ ed., 1957 (con Notas Suplementarias»). New York: Stechert \& Hafner. Reimpresiones de la 4a ed. [5a ed. 1940 . . . 28a ed., 2004] Madrid, CSIC.

- 1922. «La cantidad silábica en unos versos de Rubén Darío.» RFE 9: 1-29.

- 1930. El idioma español en el cine parlante. Con versión en inglés de A. M. Espinosa, Jr. Madrid: Tipografía de Archivos.

- 1933. «La frontera del andaluz.» Con Aurelio M. Espinosa, Jr., y L. Rodríguez Castellano. RFE 20: 225-77.

— 1934. «Análisis del valenciano literario.» Con Manuel Sanchis Guarner. RFE 21: 113-41. 
- 1937a. «Carta a un intelectual» El Mono Azul 37 (21 Oct.): 1.

— 1937b. «Message to American Teachers of Spanish.» New York: Spanish Information Bureau.

- 1938. 1936-1938: Dos años de leal amistad: España en la Unión Soviética. Barcelona: Amigos de la Unión Soviética.

- 1939. «Dédoublement de phon mes dans le dialecte. Travaux du Cercle Linguistique de Prague 8 (1939): 184-86. ADesdoblamiento de fonemas vocalicos.» RFH 1: 165-67.

- 1943. Cuestionario lingüístico hispanoamericano. 1. Fonética Morfología Sintaxis. Buenos Aires: Instituto de Filología. 2a ed., 1945.

- 1944. Manual de entonación española. New York: Hispanic Institute. 2a ed., 1948.

- 1946. Estudios de fonología española. Syracuse: Syracuse U P.

- 1948. El español en Puerto Rico. Río Piedras: U Puerto Rico.

— 1956a. «Apuntes sobre el español dominicano.» Revista Iberoamericana 21:417-29.

— 1956b. Métrica española: Reseñea histórica y descriptiva. Syracuse: Syracuse U P. 3a ed. rev. 1972. Madrid: Guadarrama.

- 1957. Documentos lingüísticos del Alto Aragón. Syracuse: Syracuse U P.

- 1968-69. «Don Ramón Menéndez Pidal en el Centro de Estudios Históricos.» Anuario de Letras [UNAM] 7: 9-24.

- 1973. Los poetas en sus versos: Desde Jorge Manrique a García Lorca. Espluges de Llobregat (Barcelona): Ariel.

- 1975. «Noticia histórica del ALPI.» En Capítulos de geografía lingüística de la Península Ibérica. Bogotá: Instituto Caro y Cuervo. 9-21.

Pérez Pascual, José Ignacio, 1998. Ramón Menéndez Pidal: Ciencia y pasión. [Valladolid]: Junta de Castilla y León, Consejería de Educación.

Quilis, ANTONio, 1993. Tratado de fonología y fonética españolas. Madrid: Gredos.

Quilis, AnTonio, y Joseph Fernández, 1964. Curso de fonética y fonología españolas para estudiantes angloamericanos. Madrid: CSIC.

Real Academia Española, 1973. Esbozo de una nueva gramática de la lengua española. Madrid: Espasa.

SALBERRIA, RAmón. 2007. Tomás Navarro Tomás: ciudadano TNT. Toledo: Consejería de Cultura de Castilla-La Mancha.

SÁnCHEZ-Ron, José M., 2007. «Tomás Navarro Tomás y los orígenes de la fonética experimental en la JAE.» Asclepio 49: 43-86.

ZAMORA Vicente, Alonso, 1979. «Tomás Navarro Tomás (1884-1979). BRAE 59: 413-31.

Zulueta, Carmen de, 2004. Caminos de España y de América. Madrid: Residencia de Estudiantes. 
